\title{
Tempos de dizer, tempos de escutar. Testimonhos de mulheres no Brasil e no Argentina
}

\author{
Danielle Tega (2019) Sao Paulo, Fapesp/Intermeios (Coleção Entregéneros), 272 pp.
}

\section{Claudia Calvo}

Instituto de Investigaciones Gino Germani, Facultad de Ciencias Sociales, Universidad de Buenos Aires/Conicet

Hasta mediados de los años noventa el campo de estudios de la memoria estuvo hegemonizado por la denuncia de los crímenes de la dictadura. Tal como lo han señalado ya diversos autores (ver, entre otros, Jelin, 2002, 2013; Catela da Silva, 2005; Oberti y Pitaluga, 2012; Oberti y Bacc, 2013),a partir de entonces los discursos públicos sobre la historia reciente asumieron un giro que desplazó el foco hacia la militancia revolucionaria, dando lugar al surgimiento de una extensa testimonialidad (Oberti, 2015: 128-129). Si bien este viraje consistió mayoritariamente en la circulación de relatos masculinos, poco a poco fueron surgiendo otras voces que enunciaron públicamente sus experiencias sobre la militancia política y la represión, en particular, testimonios de mujeres, históricamente silenciados y/o perimidos en el esfuerzo por encontrar una escucha o una audiencia.

Precisamente, este es el tema central de Tempos de dizer, tempos de escutar..., resultado de una rigurosa investigación realizada por Danielle Tega, Doctora en Sociología por la Universidad Estadual de Campinas. El libro, que es fruto de la tesis doctoral que la autora defendió a principios de 2015, pone el foco en los testimonios públicos de mujeres que escribieron y produjeron obras para ser leídas, asistidas, escuchadas. $Y$ constituye un novedoso aporte al campo de estudios de la memoria y la historia reciente, al incorporar una perspectiva de género que actualiza y tensiona las condiciones existentes de enunciación y escucha sobre el pasado, estructuradas e inscriptas en la cultura hegemónica patriarcal.

Tega examina testimonios públicos de mujeres que lucharon contra las dictaduras y padecieron la represión política en Brasil (entre 1978 y 2014) y la Argentina (entre 1984 y 2014). Los relatos no solo enuncian las características y la singularidad que asumió la violencia hacia las mujeres durante el terrorismo de Estado, sino también, reflexionan críticamente sobre la propia militancia y sobre las organizaciones a las que pertenecieron, permeadas por el machismo y el autoritarismo; y resignifican las acciones de resistencia que, como presas políticas y militantes revolucionarias, desarrollaron en condiciones de encierro. Desacatando la escasa circulación pública de relatos de mujeres sobre el pasado reciente, la autora releva exhaustivamente el material escrito y audiovisual sobre el trauma, la militancia y las resistencias que diversas mujeres realizaron sobre su propia experiencia o recuperando la experiencia de sus compañeras. ${ }^{1}$ Así, la visibilización de testimonios de mujeres que optaron por la transmisión pública de sus experiencias, el punto de partida de la investigación, abre el camino a la reflexión sobre el sentido de la manifestación pública de la propia memoria. Para ello, según Tega, fue central incorporar una perspectiva feminista de los ejercicios de memoria, con el fin de examinar las relaciones entre memoria, género y subjetividad, considerando la escritura y la realización audiovisual como espacios de reconstrucción subjetiva. En palabras de Tega, "reconstruyen la subjetividad de las mujeres que testimonian al mismo tiempo que desestabilizan la percepción tradicional tanto del pasado reciente como del presente, al crear espacios para nuevos posicionamientos, tanto para quien narra como para quien escucha" (2018: 22). Con ello, Tempos de dizer... constituye un aporte

1 De ese modo, la autora continúa una línea de investigación iniciada con la defensa de su tesis de maestría, publicada como libro en 2010 bajo el título Mulheres em foco: construções cinematográficas brasileiras da participação política feminina. 
fundamental en el campo académico, para los estudios de género y los estudios de memoria y la historia reciente, como una herramienta de análisis para la lucha por los derechos humanos y el activismo feminista en varios sentidos. Primero, porque examina la perspectiva de las mujeres que militaron en organizaciones revolucionarias, respecto de la propia militancia y los procesos de resistencia adoptados durante las dictaduras, contribuyendo a la reflexión sobre los esfuerzos de despatriarcalización de las organizaciones y el activismo político en la actualidad; segundo, por el riguroso análisis del material literario y cinematográfico como herramienta y objeto de investigación a la vez; tercero, porque aporta una mirada comparativa entre los testimonios de argentinas y brasileras, reconociendo similitudes en las estrategias de resistencia y reconstrucción subjetiva de las mujeres frente a la represión padecida, signada por la presencia de la afectividad y la amistad en las formas de solidaridad y amparo.

El libro está dividido en seis capítulos. En el primero, "Sobre el testimonio", se exponen presupuestos teóricos ligados a la cuestión del trauma y el testimonio. Allí, Tega presta especial atención al problema de la escucha y la presencia de un otro que pueda recibir las palabras de quien narra. Además, desde una perspectiva feminista, problematiza las disputas en torno al pasado, considerando que ciertos relatos pueden crear fisuras en las narrativas hegemónicas. Los capítulos segundo y tercero, "Políticas de memoria y testimonios en Brasil (1978-2014)" y "Políticas de memoria y testimonios en Argentina (1984-2014)", respectivamente, tienen como objetivo relevar de forma inédita los testimonios escritos o audiovisuales producidos por mujeres cuyas vidas estuvieron atravesadas, de diferentes formas, por las dictaduras militares de Brasil y la Argentina. En cada capítulo la autora presenta cada testimonio destacando los aspectos de la obra que articulan el relato con las relaciones de género. Este recuento testimonial, a su vez, incluye una paralela descripción de las políticas de memoria realizadas en ambos países durante el período examinado. El cuarto capítulo, "Militancias políticas, afectos clandestinos", consiste en un análisis del libro No corpo, na alma de Derlei Catarina De Luca (militante de la organización Acción Popular² y ex presa política), publicado en 2002. Tega analiza los modos de narración adoptados por la autora y examina temas vinculados a las relaciones de género 2 La Acción Popular (AP) surgió en 1962 como organización autónoma, inicialmente vinculada a la Iglesia Católica y al movimiento estudiantil. Después del golpe, la AP adhiere a la proletarización, con el objetivo de compartir la práctica social de la clase obrera y campesina. en la clandestinidad, la cuestión de la disciplina de las organizaciones, la descripción del embarazo y/o el nacimiento de los hijos, abonando lúcidamente a una reflexión más general ligada a las relaciones entre experiencia y género, entre escritura y testimonio, entre subjetividad y memoria. El quinto capítulo, "Corpos de batalha", analiza la represión estatal sobre los cuerpos y las subjetividades de las mujeres y se enfoca en la narración del trauma, problema que coloca en escena el conflicto entre el lenguaje y lo acontecido. Para ello, Tega examina dos filmes: el temprano Que bom te ver viva (1989) de la brasilera Lucía Murat, quien fue militante del MR-83 y ex presa política; y Campo de Batalla, cuerpo de mujer (2013) dirigido por Fernando Álvarez y Lizel Tornay, ex detenidos desaparecidos quienes en el momento de su detención no participaban orgánicamente de ninguna organización. Producidos en contextos bastante distintos, ambos filmes manifiestan la especificidad del género en la tortura y en la apropiación de los cuerpos femeninos, en tanto prácticas sistemáticas ligadas a sentidos de género en disputa, como también los problemas relacionados con el embarazo y la maternidad en los contextos represivos. Tega examina los materiales visuales y sonoros puestos en escena en los filmes, atendiendo al estudio del lenguaje cinematográfico. Siguiendo a la autora "tanto los testimonios vertidos por las entrevistadas, como los documentales en tanto obras testimoniales, crean una tensión en las relaciones entre habla y escucha en ambas sociedades y manifiestan la necesidad de crear nuevos vínculos con la vida" (2018: 25). Al respecto, logra un riguroso análisis de la función del testimonio en los procesos de recreación de las subjetividades: por un lado, al indagar en las reflexiones que los relatos hacen sobre el embarazo y la maternidad en contextos de clandestinidad y encierro; por el otro lado, al examinar cómo varios testimonios se esfuerzan por rescatar al sobreviviente del sitio de la otredad negativa. Con ello, además, Tega hace hincapié en el proceso de resignificación, que puede no aparecer en el momento narrado pero sí en el momento de la narración y que vuelve al testimonio de las mujeres un instrumento de lucha, resistencia y agenciamiento, de ahí su capacidad de enriquecer los debates del campo de la memoria y la historia reciente. El sexto y último capítulo analiza el modo en que los testimonios articulan, en sus narrativas actuales, la acción de

3 El Movimiento Revolucionario 8 de Octubre (MR-8) se construyó entre jóvenes del movimiento estudiantil y disidentes del Partido Comunista Brasileño (PCB). La organización actuó como un grupo guerrillero urbano y fue responsable, juntamente con la Acción Libertadora Nacional (ALN), por el secuestro de Charles Burke Elbrick, entonces embajador de Estados Unidos en Brasil, en septiembre de 1969. 
escucha con otras mujeres (compañeras de celda) y de amparo de los cuerpos y las subjetividades. Para ello examina el documental argentino Memoria de un escrito perdido (2010) dirigido por Cristina Raschia, quien fue militante barrial ligada a la teología de la liberación y estuvo presa por motivos políticos en 1975, previo al golpe de estado. Raschia cuenta su historia en la prisión a partir de la experiencia colectiva de un grupo de mujeres que integró en la cárcel de Villa Devoto. A partir del reencuentro de esas mujeres veinte años después, el filme pone el foco en las estrategias colectivas de solidaridad realizadas en contextos represivos, las cuales, según Tega, explican una primera instancia de preservación del sujeto y el amparo frente a los efectos psíquicos y físicos de la violencia sufrida durante la tortura. En este caso, la autora recupera la potencialidad de la escucha, como aspecto central para que los testimonios funcionen como procesos de resignificación de la propia experiencia, es decir, la existencia de un “acogimiento sociocultural”, una condición para la posterior creación de nuevas formas de intervención política de muchas de esas mujeres en el movimiento de DD.HH. y/o el feminismo. Tega sugiere que el filme es en sí mismo una forma de acogimiento y amistad. Las consideraciones finales del libro hacen hincapié en la pertinencia de la adopción de una perspectiva feminista para la investigación del pasado reciente, al brindar novedosas claves de lectura para el campo de estudios: el examen de la violencia sexual en su dimensión sistémica y estructural, la revisión de las prácticas militantes signadas por la cultura patriarcal, la importancia de la afectividad y el cuidado entre compañeras por encima de las diferencias políticas y/u organizativas, y su potencialidad para la recreación de sociabilidades y resistencias aun en contextos represivos y situaciones de encierro, entre otras. Estas claves de lectura constituyen las principales contribuciones del libro, y son el resultado de la perspectiva analítica escogida por la autora, esto es, trabajar con los documentos escritos y audiovisuales como objeto de estudio, como de producciones testimoniales en sí mismos y no meros instrumentos de investigación. Al dialogar con el pensamiento feminista, el examen de los recursos cinematográficos como trabajos de memoria explica su potencialidad transformadora: su dimensión pública (producidos para ser escuchados), el estar orientados a la interpelación de las condiciones de escucha y habla existentes, el profundizar los procesos de transmisión de la experiencia de las mujeres y entre mujeres. De ahí la importancia política de Tempos de dizer, tempos de escutar, como continuación de ese trabajo de transmisión y de escucha.

Para concluir, el análisis testimonial que realiza Tega hace referencia a la dimensión política de la lucha por el pasado, y al carácter inconcluso de los procesos de memoria. En efecto, Tempos de dizer, tempos de escutar fue publicado en 2018 en Brasil, en un contexto político nacional y regional muy distinto a aquel en el que Tega realizó su investigación. Hacia fines de 2014, momento en el cual la autora culminó la escritura de su tesis, la Comisión Nacional de la Verdad entregó su informe final dando inicio a una nueva etapa en las políticas de memoria en Brasil. Desde entonces hasta su publicación, tres años más tarde, significativas transformaciones tuvieron lugar en el ámbito político, económico y social. Tega describe estos cambios a partir del surgimiento de dos fenómenos simultáneos. Por un lado, el ascenso de la derecha por la vía legal democrática en diversos países del continente: la llegada al gobierno de la extrema derecha en 2018 tras la elección de Jair Bolsonaro como presidente, cuyas consecuencias en las diferentes esferas de la vida social brasilera aún están en curso; pero también las victorias de los derechistas Mauricio Macri en la Argentina (2015) y Donald Trump en Estados Unidos en 2016. Por el otro lado, la emergencia del movimiento de mujeres que tomó las calles de diversos países en América Latina y que, según la autora, contribuyen a la ampliación de los marcos sociales de enunciación y escucha de experiencias marcadas por la represión y la resistencia. En ese sentido para Tega "no son accidentales los ataques a mujeres con el proceso político que se abrió en Brasil a partir de 2018" y por ello "retomar este texto luego de esos acontecimientos fue inquietante" puesto que el resultado de las elecciones de 2018 representaba, en varios sentidos, la derrota de la tesis que había defendido tres años antes, y afirma que "una vez más, las mujeres que lucharon contra la dictadura y las trayectorias de aquellas que aun hoy luchan por justicia social, son vilipendiadas. Pero, al mismo tiempo, ese mismo resultado refuerza la importancia política y académica de este libro (2018: 28). 


\section{Q Bibliografía}

"Bacci, C. y Oberti, A. (2013). El futuro de las revoluciones. Una reflexión teórico metodológica de los testimonios de militantes revolucionarios de los 60 y 70 en Argentina. Ponencia presentada en el XXXI International Congress of the Latin American Studies Association "Towards a New social contract". LASA.

»Da Silva Catela, L. (2005). Desaparición, violencia política y dictadura en Argentina. Mapas de la violencia, políticas y ciclos de las memorias. Ponencia presentada en el Taller del Seminario Internacional sobre Memoria e Historia. Guatemala, C.A.
" Jelin, E. (2002). Los trabajos de la memoria. Madrid, Siglo XXI.

»------. (2013). Militantes y combatientes en la historia de las memorias: silencios, denuncias y reivindicaciones. Meridional, revista Chilena de Estudios Latinoamericanos, № 1: 77-97.

"Oberti, A. (2015). Las Revolucionarias. Militancia, vida cotidiana y afectividad en los setenta. Buenos Aires, Edhasa.

»Oberti, A. y Pitaluga, R. (2012). Memorias en Montaje. Escrituras de la militancia y pensamiento sobre la historia. Santa Fe, María Muratore. 